\title{
Matrine-induced autophagy regulated by p53 through AMP-activated protein kinase in human hepatoma cells
}

\author{
SHAN-BU XIE ${ }^{1,3}$, XING-XING $\mathrm{HE}^{1}$ and SHU-KUN YAO ${ }^{2.3}$ \\ ${ }^{1}$ The Department of Gastroenterology, The First Affiliated Hospital of Nanchang University, \\ Nanchang 330006; ${ }^{2}$ The Department of Gastroenterology, China-Japan Friendship Hospital, \\ Ministry of Health, Beijing 100029; ${ }^{3}$ The Graduate School, Peking Union Medical College \\ and Chinese Academy of Medical Sciences, Beijing 100730, P.R. China
}

Received October 25, 2014; Accepted December 29, 2014

DOI: $10.3892 /$ ijo.2015.3023

\begin{abstract}
Matrine, one of the main extract components of Sophora flavescens, has been shown to exhibit inhibitory effects on some tumors through autophagy. However, the mechanism underlying the effect of matrine remains unclear. The cultured human hepatocellular carcinoma cell line HepG2 and SMMC-7721 were treated with matrine. Signal transduction and gene expression profile were determined. Matrine stimulated autophagy in SMMC-7721 cells in a mammalian target of rapamycin (mTOR)-dependent manner, but in an mTORindependent manner in HepG2 cells. Next, in HepG2 cells, autophagy induced by matrine was regulated by p53 inactivation through AMP-activated protein kinase (AMPK) signaling transduction, then AMPK suppression switched autophagy to apoptosis. Furthermore, the interferon (IFN)-inducible genes, including interferon $\alpha$-inducible protein 27 (IFI27) and interferon induced transmembrane protein 1 (IFITM1), which are downstream effector of $\mathrm{p} 53$, might be modulated by matrineinduced autophagy. In addition, we found that the p53 protein isoforms, $\mathrm{p} 53 \beta, \mathrm{p} 53 \gamma, \Delta 133 \mathrm{p} 53$, and $\Delta 133 \mathrm{p} 53 \gamma$, due to alternative splicing of intron 9 , might be regulated by the p53-mediated autophagy. These results show that matrine induces autophagy in human hepatoma cells through a novel mechanism, which is p53/AMPK signaling pathway involvement in matrinepromoted autophagy.
\end{abstract}

\section{Introduction}

Matrine is one of the main components extracted from Sophora flavescens (1), and matrine has been widely applied in the treatment of a variety of tumors including hepatocellular carcinoma (HCC) (2). It has been indicated that matrine can inhibit proliferation and then induce apoptosis and autophagy of certain

Correspondence to: Professor Shu Kun Yao, Department of Gastroenterology, China-Japan Friendship Hospital, Ministry of Health, Beijing 100029, P.R. China

E-mail: yaoshukun6@yahoo.com.cn

Key words: autophagy, matrine, p53, isoform, AMP-activated protein kinase, interferon types of tumor cells $(3,4)$, e.g., C6 glioma cells and hepatoma G2 cells $(5,6)$. Autophagy is a catabolic process involved in degradation of the cellular components such as long-lived proteins and organelles, through the lysosomal machinery (7). Although initially identified as a process induced by cellular starvation, autophagy is currently recognized as the cellular adaptation to a variety of stimulations (8). However, the role of autophagy in cancer is not clear. In some settings, autophagy delays apoptosis in response to chemotherapy (9). Inhibition of autophagy enhances drug-induced apoptosis in human cancer lines (10-14). In other settings, antitumor agents augment autophagic cell death.

The tumor suppressor p53 can maintain the integrity of genome DNA, regulate cell cycle progression and cell death, and thus, play a central role in response to stress (15). Autophagy, like apoptosis and cell cycle progression, is associated with p53 (15). The tumor suppressor p53 activates autophagy through its downstream targets. It has been shown that p53 interacts with mammalian target of rapamycin (mTOR) through AMP-activated protein kinase (AMPK) $(16,17)$. However, the role of p53 signaling in regulation of autophagy remains to be studied.

The molecular mechanism of autophagy induction by matrine is not well studied so far. In this study, we found matrine-induced autophagy was mediated by p53/AMPK signaling pathway. Furthermore, for the first time, we demonstrated that p53 isoforms and the interferon (IFN)-inducible genes, i.e., IFI27 and IFITM1, might be regulated by the p53-mediated autophagy induction by matrine. The present study shed new insight into the mechanism of autophagy induction by matrine.

\section{Materials and methods}

Reagents. 3-Methyladenine (3MA), rapamycin, dimethylsulfoxide (DMSO), compound c and antibody against microtubule-associated protein 1 light chain 3 (LC3) were purchased from Sigma Chemical Co. (St. Louis, MO, USA). Antibodies against p70S6 (Thr389), AMPK (Thr172), p-ACC (Ser79), p-Akt (Thr473) and p-Erk1/2 (Thy202/Tyr204) were provided commercially by Cell Signaling Technology, Inc. (Beverly, MA, USA), and p62, $\beta$-actin and p53 by Santa Cruz 
Biotechnology (Santa Cruz, CA, USA). Z-VAD-fmk was purchased from Promega (Madison, WI, USA). Constitutively active p53 was kindly donated by Dr Zhixin Zheng (Peking University School of Medicine, Peking, China). GFP-LC3 plasmid was kindly donated by Dr Mengqiang Li (Peking University School of Medicine, Peking, China). Matrine was purchased from the National Institute for the Control of Pharmaceutical and Biological Products (Peking, China).

Cell line and cell culture. HepG2 and SMMC-7721 cells were purchased from ATCC, and cultured in a $25-\mathrm{cm}^{3}$ flask with Dulbecco's modified Eagle's medium (Invitrogen, Carlsbad, CA, USA) supplemented with $10 \%$ (v/v) fetal bovine serum (FBS) (Invitrogen), $100 \mathrm{U} / 1$ penicillin (Invitrogen), and $100 \mathrm{mg} / \mathrm{l}$ streptomycin (Invitrogen). The cells were treated with matrine for $48 \mathrm{~h}$, and collected for further study thereafter.

Confocal microscopy. Cells were incubated with monodansylcadaverine (MDC, $0.05 \mathrm{mM}$ ), which was purchased from Sigma Chemical Co. After $1-\mathrm{h}$ incubation at $37^{\circ} \mathrm{C}$, the cells were fixed in $4 \%$ paraformaldehyde for $15 \mathrm{~min}$ and immediately analyzed using a scanning confocal microscope (Olympus, Japan).

Cells at $\sim 60 \%$ confluence were transfected with GFP-LC3 using Vigofect (Vigorous, Peking, China), $24 \mathrm{~h}$ later, and cells were subjected to various treatments and then detected by a scanning confocal microscope (Olympus, Japan). Percentages of punctuate distribution of GFP-LC3 dots were calculated in five non-over-lapping fields.

Electron microscopy. The trypsinized cells were fixed with ice-cold glutaraldehyde ( $3 \%$ in $0.1 \mathrm{M}$ cacodylate buffer, $\mathrm{pH}$ 7.4) for $30 \mathrm{~min}$. After fixation in $\mathrm{OsO}_{4}$, the cells were embedded in Epon, and stained with uranyl acetate/lead citrate (Fluka, Buchs, Switzerland). Observation was performed on a JEM1230 electron microscope (JEOL, Japan).

Flow cytometry analysis. Cells were treated with the indicated concentrations of chemotherapeutic agents for $48 \mathrm{~h}$, followed by staining with Annexin V-fluorescein isothiocyanate (FITC) (BD Pharmingen, CA, USA) and propidium iodide (PI) (BD Pharmingen), and subsequently, analyzed by flow cytometry (FACSAria, Becton-Dickinson, USA).

Isolation of RNA and cDNA microarray assay. Total RNA was extracted from matrine-treated HepG2 cells using the TRIzol reagents (Invitrogen). The cDNA microarray analysis was performed by CapitalBio Co. (Peking, China) according to the standardized protocol. A Lux-Scan 10KA dual pathways laser scanner (CapitalBio) and a GenePix Pro 4.0 image analysis software (Axon Instruments, Inc., Union City, CA, USA) was applied to scan the chips and analyze the images, respectively. The raw image files of all the data were normalized and analyzed. Annotation was in correspondence with Unigene database http://www.ncbi.nlm.nih.gov/unigene, including gene number and gene symbol. Ratio values $>2$-fold upregulation or downregulation $(\mathrm{p}<0.05)$ was regarded as significantly expressed genes.

Reverse transcription-polymerase chain reaction (RT-PCR) and real-time $P C R$. One microgram of total RNA was reverse- transcribed into cDNA using cDNA reverse transcription kits (Invitrogen). Hot-start PCR was then performed (Eppendorf, Germany). The PCR results were verified by varying the number of PCR cycles for each cDNA and set of primers. The target gene primer pairs were as follows: IFI27 upper primer: GGCCAGGATTGCTACAGTTGTGATT; lower primer: GCGGACATCATCTTGGCTGCTAT; IFITM1 upper primer: TAGCATTCGCCTACTCCGTGAA, lower primer: AGCCGA ATACCAGTAACAGGATGAA; CASP1 upper primer: TGAAGGACAAACCGAAGGTGA, lower primer: TGTGGA AGAGCAGAAAGCGATA; p53 upper primer: CTCCAG CCACCTGAAGTC, lower primer: GTCAGTGGGG AACAAGAAG; p53 $\beta$ upper primer: ATGGAGGAGCC GCAGTCAGAT, lower primer: TTGAAAGCTGGTCTGG TCCTGA; p53 $\gamma$ upper primer: ATGGAGGAGCCGCA GTCAGAT, lower primer: TCGTAAGTCAAGTAGCATCT GAAGG; $\triangle 133$ p53 upper primer: TGGGTTGCAGGAGG TGCTTA, lower primer: CTCACGCCCACGGATCTGA; $\Delta 133$ p53 $\beta$ upper primer: TGGGTTGCAGGAGGTGCTTA, lower primer: TGGGTTGCAGGAGGTGCTTA; $\Delta 133 \mathrm{p} 53 \gamma$ upper primer: TGGGTTGCAGGAGGTGCTTA, lower primer: TCGTAAGTCAAGTAGCATCTGAAGG (20); GAPDH upper primer: ACGGATTTGGTCGTATTGGG, lower primer: TGATTTTGGA GGGATCTCGC. The amplified products were separated on 2 and $1.5 \%$ agarose gels and visualized under ultraviolet transillumination.

Real-time PCR was performed by pre-denaturation at $95^{\circ} \mathrm{C}$ for $10 \mathrm{~min}$, followed by 40 cycles of $95^{\circ} \mathrm{C}$ for $15 \mathrm{sec}$ and $60^{\circ} \mathrm{C}$ for $1 \mathrm{~min}$. The data were analyzed with $\Delta \mathrm{Ct}$ method according to the manufacturer's instructions (Applied Biosystems, CA, USA). The data were normalized to the housekeeping gene GAPDH. Changes in gene expression were illustrated as a fold increase/decrease. The experiments were repeated three times.

RNA interference. Cells were seeded at 30-50\% confluence per well in 6-well plates overnight and transfected with target gene specific siRNA or control siRNA duplex (Santa Cruz Biotechnology, Inc.), and then cultured with various treatments. Blockage of target gene was successfully examined by immunoblotting analysis.

Western blot analysis. Proteins obtained from cell lysates (40 $\mu \mathrm{g}$ protein/lane) were separated on SDS-PAGE by electrophoresis, and transferred to nitrocellulose membranes. The membranes were incubated with the primary antibodies, and then probed with secondary antibodies. The specific bands were visualized using an enhanced chemiluminescence system (Pierce Biotechnology, Inc., Rockford, IL, USA).

Statistical analysis. Data are expressed as mean \pm SEM. The number of individual experiments is described in the figure legends. Statistical analysis was performed using SPSS 17.0 statistics software (SPSS, Inc., Chicago, IL, USA). P-values $<0.05$ were considered as statistically significant.

\section{Results}

Matrine inhibits proliferation and induces apoptosis of human hepatoma cells. Matrine has been reported to promote apoptosis in previous in vitro studies $(21,22)$. To study the 
Matrine $(\mathrm{mg} / \mathrm{ml}) \quad 0$

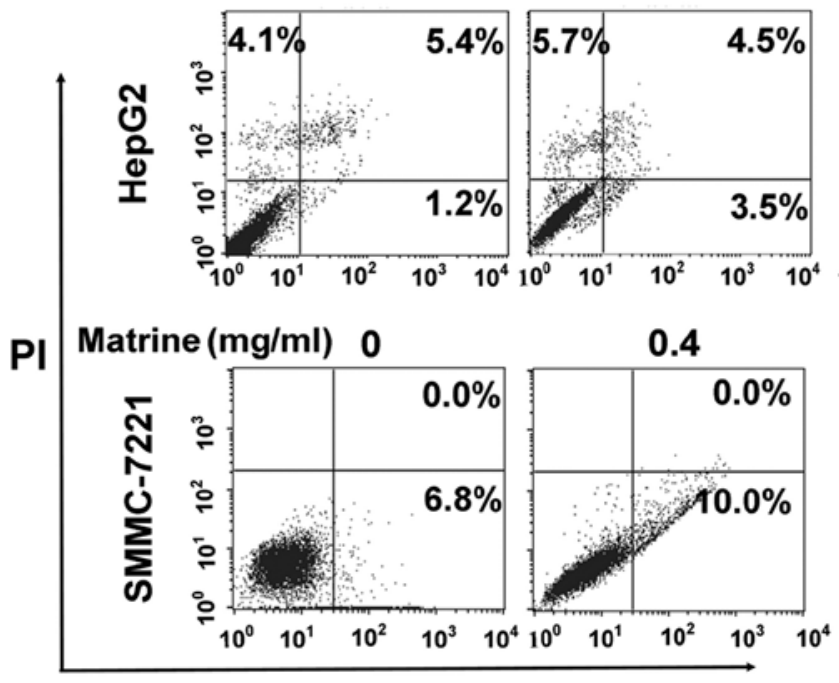

0.8

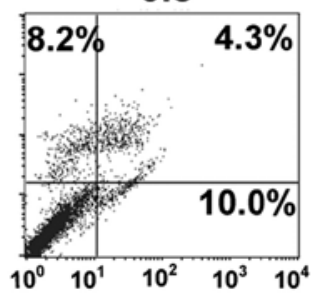

0.8

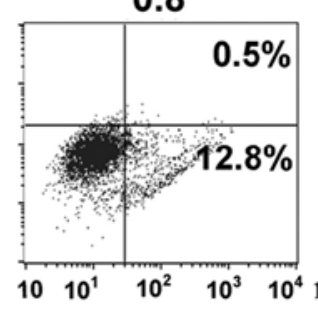

1.6

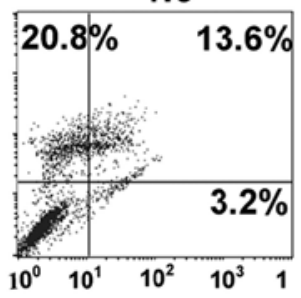

1.6

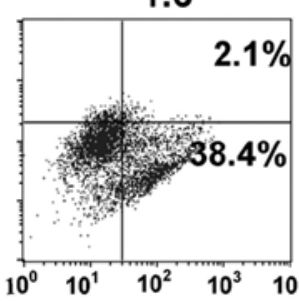

3.2

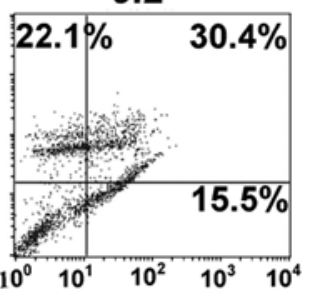

3.2

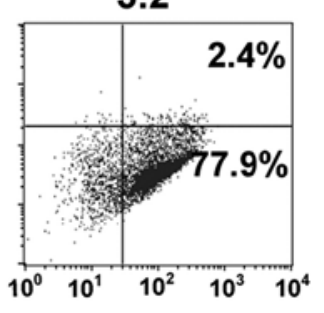

ANNEXIN-V

Figure 1. Matrine promotes apoptosis on HepG2 and SMMC-7721 cells. The hepatoma cells, including HepG2 and SMMC-7721 cells, were incubated with matrine at different concentration for $48 \mathrm{~h}$, and percentage of apoptotic cells were then detected by Annexin V/PI analysis through flow cytometry. Similar results were obtained from three independent experiments.

effect of matrine on proliferation and apoptosis of human hepatoma cells, we treated HepG2 cells and SMMC-7721 cells with different doses of matrine for $48 \mathrm{~h}$, and detected apoptosis of the cells, respectively. As shown in Fig. 1, at low dose of $0.8 \mathrm{mg} / \mathrm{ml}$, matrine induced a slight increase of apoptosis of HepG2 cells and SMMC-7721 cells as compared with the untreated cells, while matrine induced a significant elevation in apoptosis level at median dose of $1.6 \mathrm{mg} / \mathrm{ml}$ and at large dose of $3.2 \mathrm{mg} / \mathrm{ml}$.

Matrine stimulates autophagy in human hepatoma cells. The number of MDC-stained punctuate structure, an indicator of autophagosomes, was significantly increased in human hepatoma cell lines after exposure to matrine at low dose of $0.4 \mathrm{mg} / \mathrm{ml}$, and reached a peak at $0.8 \mathrm{mg} / \mathrm{ml}$, then a slight decrease at $1.6 \mathrm{mg} / \mathrm{ml}$ (Fig. 2A). Based on these results, treatment with $0.8 \mathrm{mg} / \mathrm{ml}$ of matrine for $48 \mathrm{~h}$ was used for further studies on autophagy in hepatoma cells.

LC3, a mammalian homologue of Atg8, is widely used as a specific marker for detecting autophagy (23). As shown in Fig. 2B, confocal microscopy assay showed the significant increase of the punctuate GFP-LC3 in matrine-treated cells, which was in line with MDC staining analysis. Similar results were observed through immunoblotting assay. P62/ SQSTM1, as a substrate of autophagy, was selectively degraded by auto-lysosomes. Autophagy inhibition promoted the accumulation of p62/SQSTM1. The degradation of p62/SQSTM1 was detected in matrine-treated cells through western blot analysis (Fig. 2B). Transmission electron microscopy (TEM), one of the most reliable methods for detecting autophagy (24), demonstrated that autophagic vacuoles were easily observed in both hepatoma cell types exposed to matrine at $0.8 \mathrm{mg} / \mathrm{ml}$ (Fig. 2C). These results indicated that autophagy was activated by matrine in human hepatoma cells. Furthermore, we analyzed whether matrine-induced autophagy is regulated by mTOR kinase, a central regulator for autophagy. Phosphorylation of p70S6K at Thr389, a downstream effector of mTOR and widely considered to reflect mTOR activity, was downregulated in matrine-treated SMMC-7721 cells, but upregulated prominently in matrine-treated HepG 2 cells, compared with untreated cells, suggesting that induction of autophagy by matrine was through an mTOR-dependent manner in SMMC7221 cells, but an mTOR-independent manner in HepG2 cells (Fig. 2D).

Matrine-induced autophagy involves p53 inactivation via AMPK signaling pathway. We then investigated the molecular mechanism of matrine-induced autophagy in HepG2 cells. We first examined PI3K-Akt and MAPK/ERK signaling pathways, which are associated with autophagy. A decrease of Akt and ERK phosphorylation was detected in matrine-treated cells as compared with control (Fig. 3A). Then, we analyzed the AMPK activity, which plays an important role in regulating autophagic activities. A slight elevation on AMPK phosphorylation at Thr172 was observed after matrine treatment at the dose of 0.8 and $1.6 \mathrm{mg} / \mathrm{ml}$. Consistently, similar results were obtained from analysis of phosphorylation of acetyl-CoA carboxylase (ACC), a substrate of AMPK. This suggests that AMPK signaling pathway participates in matrine-induced autophagy (Fig. 3B). Accumulating evidence has shown that the p53 tumor suppressor gene is implicated in autophagic activity via the AMPK signaling pathway (17). Furthermore, we investigated whether p53 regulates AMPK and thus activates matrine-induced autophagy. Immunoblotting analysis showed that p53 suppression was detected in HepG2 cells under matrine treatment (Fig.3C). Subsequently, after transfecting matrine-treated cells with p53 overexpression plasmid, a remarkable increase of p53 was observed. The ratio of LC3-II/ $\beta$-actin and AMPK phosphorylation at Thr172 was reversely alleviated as compared with cells transfected with 
A

Matrine (mg/ml) 0

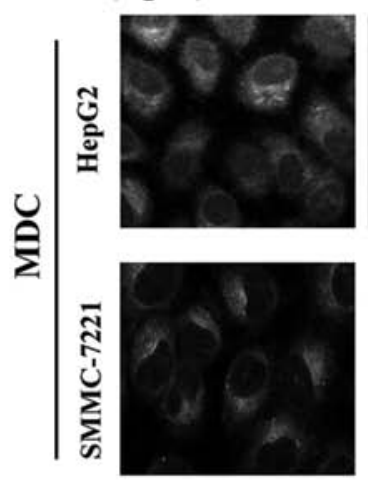

B
0.4

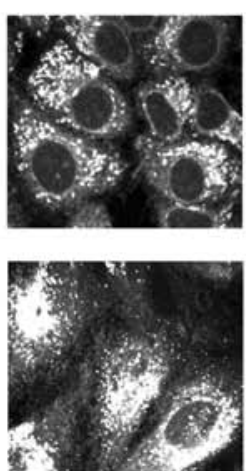

0.8

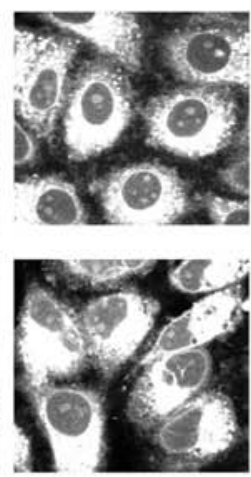

1.6

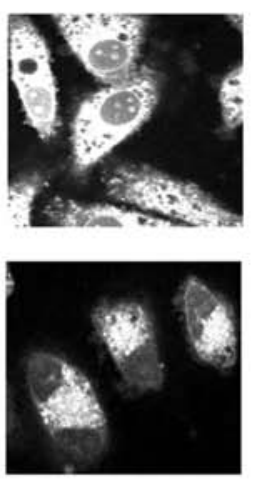

1.6

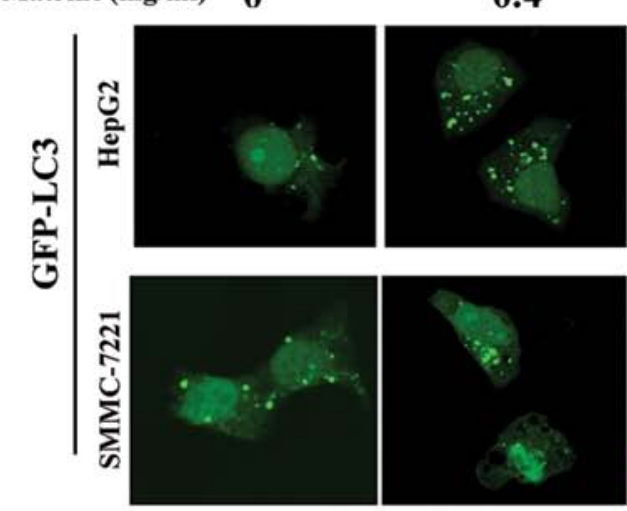

HepG2

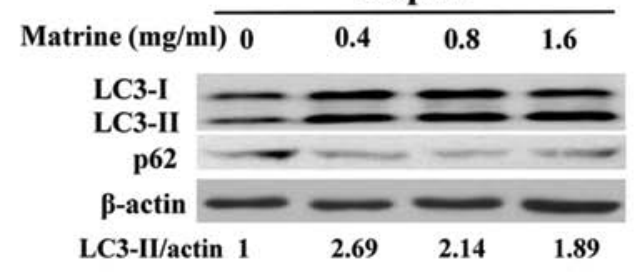

0.8

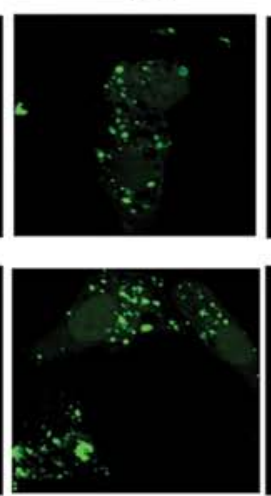

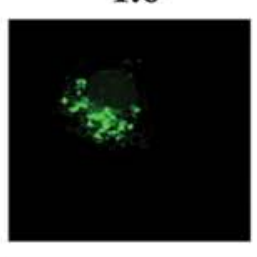

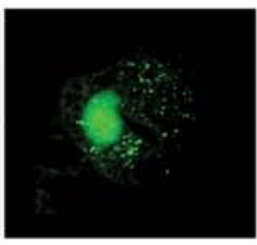

SMMC-7221
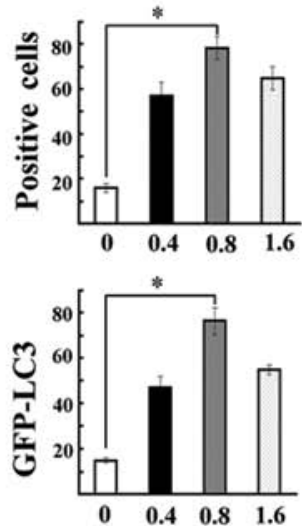

$\mathrm{C}$

\begin{tabular}{lll} 
& HepG2 \\
\cline { 2 - 3 } & \multicolumn{3}{c}{0.8}
\end{tabular}
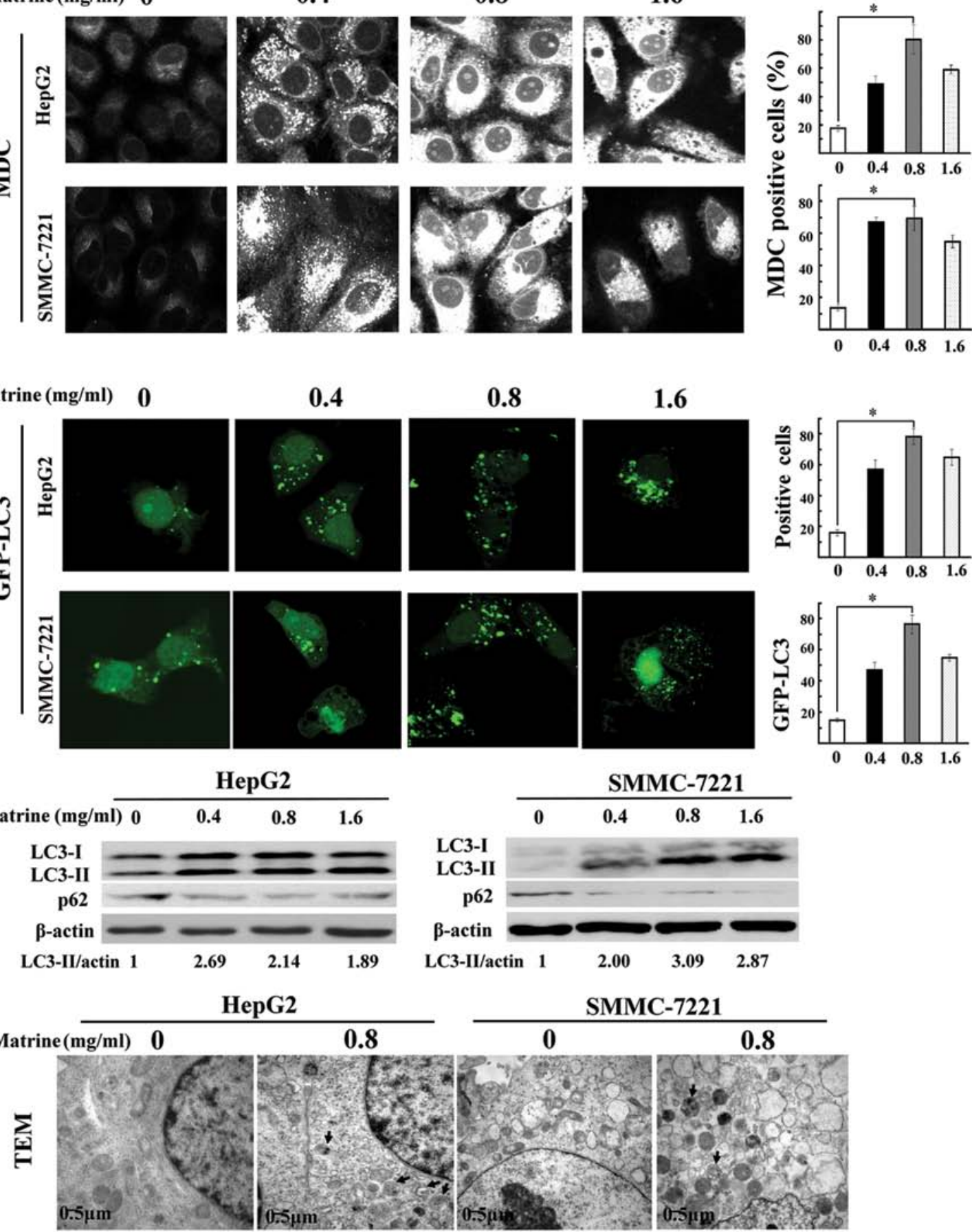

$\mathrm{D}$

\begin{tabular}{cccccccccc} 
& \multicolumn{3}{c}{ HepG2 } & & \multicolumn{3}{c}{ SMMC-7221 } \\
\cline { 2 - 3 } $\begin{array}{c}\text { Matrine } \\
\text { p-p70S6k } \\
\text { (Thr389) } \\
\beta \text {-actin }\end{array}$ & 0 & 0.4 & 0.8 & 1.6 & 0 & 0.4 & 0.8 & 1.6 \\
\hline
\end{tabular}

Figure 2. Matrine induces autophagy in HepG2 cells and in SMMC-7721 cells. (A) After exposure to matrine with 0.4, 0.8 and $1.6 \mathrm{mg} / \mathrm{ml}$, representative images of MDC staining were viewed by confocal microscopy. The significant difference of MDC-positive cells (\%) in matrine-treated cells compared to untreated cells was observed. MDC-positive cells (\%) treated by $0.8 \mathrm{mg} / \mathrm{ml}$ matrine are presented as the mean \pm SEM from three independent experiments ("p $<0.05$ ). (B) Upper panel, the cells initially were transiently transfected with GFP-LC3 plasmid for $24 \mathrm{~h}$ followed by exposure to matrine in various concentration for $48 \mathrm{~h}$, representative images of GFP-LC3 dots were viewed by confocal microscopy. The significant difference of GFP-LC3-positive cells (\%) in matrinetreated cells compared to untreated cells is presented. GFP-LC3-positive cells (\%) treated by $0.8 \mathrm{mg} / \mathrm{ml}$ matrine are presented as the mean \pm SEM from three independent experiments ( $\mathrm{p}<0.05$ ). Lower panel, cell lysates, untreated and treated with matrine in various concentration for $48 \mathrm{~h}$, were prepared and subjected to immunoblotting with antibodies to LC3, p62 and $\beta$-actin. The densitometry was performed for quantification (LC3-II/actin). (C) After exposure to matrine at the dose of $0.8 \mathrm{mg} / \mathrm{ml}$, representative electron microscopic images were obtained from matrine-treated cells as compared with control. The typical autophagosomes or autolysosomes are denoted by the arrows. (D) Immunoblot analysis of the expression of p-p70s6K (Thr389) in matrine-treated cells compared to the untreated cells. $\beta$-actin was performed as a control. 


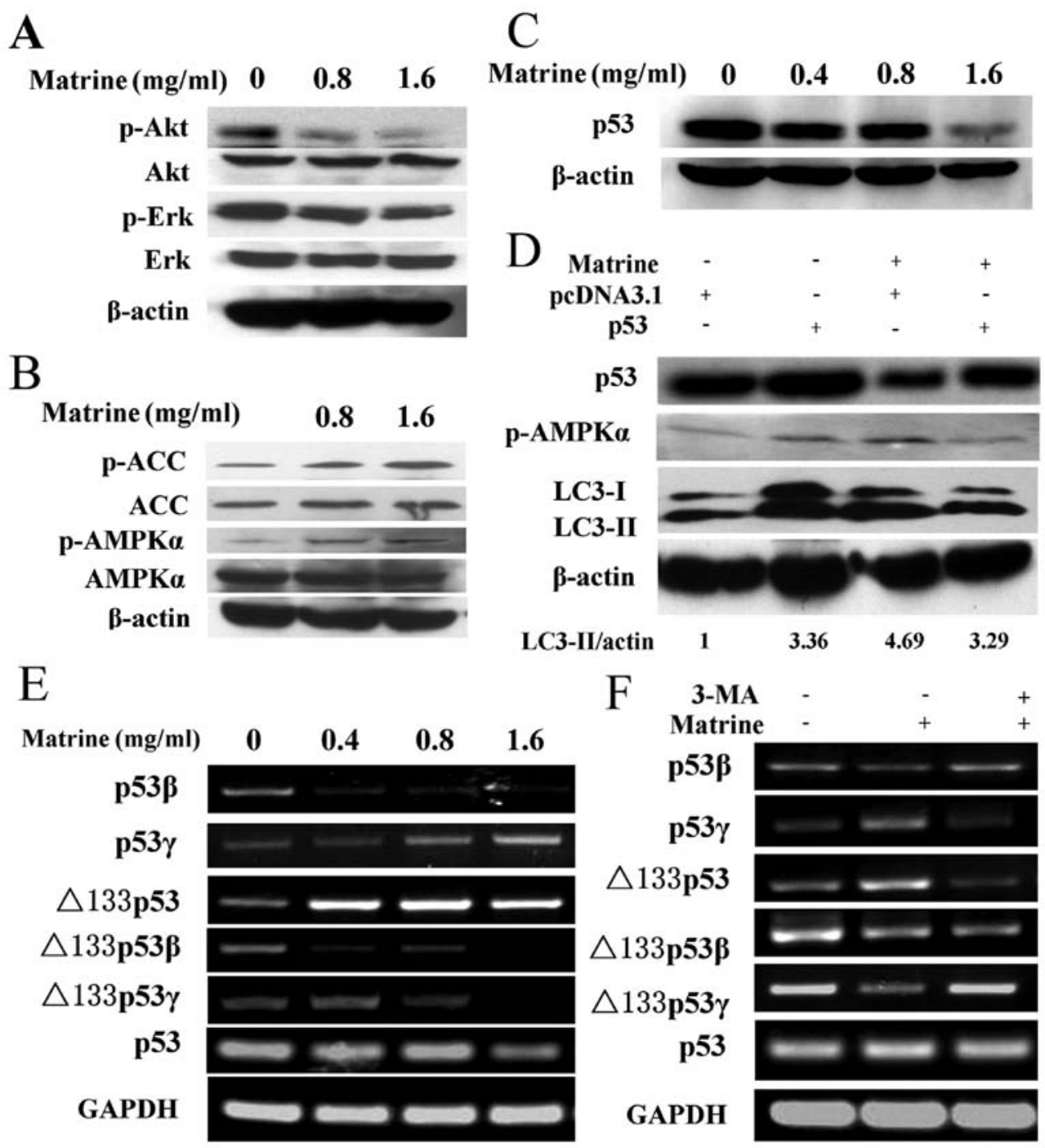

Figure 3. Matrine-induced autophagy is via p53/AMPK pathway, and p53 variants were converted by autophagy inhibition. (A) Immunoblotting analysis of the expression of p-Akt (Thr473) and p-ERK (Thy202/Tyr204) in HepG2 cells after exposure to matrine with 0.8 and $1.6 \mathrm{mg} / \mathrm{ml}$, as compared with control (B) Western blot analysis of the expression of p-AMPK $\alpha$ (Thr172) and p-ACC (Ser79) in treated cells, as compared with control. (C) After exposure to matrine with $0.4,0.8$ and $1.6 \mathrm{mg} / \mathrm{ml}$, western blot analysis of p53 levels in matrine-treated cells in comparison with control. (D) The cells initially were transiently transfected with p53 expression vector for $24 \mathrm{~h}$ followed by exposure to matrine at the dose of $0.8 \mathrm{mg} / \mathrm{ml}$ for $48 \mathrm{~h}$. Western blot analysis of p53, LC3 and p-AMPK $\alpha$ in matrine-treated cells containing p 53 overexpression vector in comparison with control vector. (E) RT-PCR analysis of p53 and its isoforms-p53 $\beta$, $\mathrm{p} 53 \gamma, \Delta 133 \mathrm{p} 53, \Delta 133 \mathrm{p} 53 \beta$ and $\Delta 133 \mathrm{p} 53 \gamma$ in the cells under matrine treatment at different dose, in contrast to control. (F) Matrine at the dose of $0.8 \mathrm{mg} / \mathrm{ml}$ in combination with $5 \mathrm{mM}$ of 3-MA is presented. RT-PCR analysis of p53 and its splice variants between matrine alone and matrine cotreated with 3-MA.

the pcDNA 3.1 empty vector (Fig. 3D). These results suggest that matrine-induced autophagy is negatively regulated by $\mathrm{p} 53$ through AMPK signaling transduction.

The $p 53 \beta$ and $\Delta 133 p 53 \gamma$ isoforms are upregulated by 3-MA, whereas the $p 53 \gamma$ and $\Delta 133 p 53$ variants are downregulated by 3-MA. Moreover, to determine whether the human p53 mRNA splice variants are linked to the matrine-induced autophagy, we amplified splice variants of p53 mRNA, including p53 $\beta$, p53 $\gamma, \Delta 133$ p53, $\Delta 133$ p53 $\beta$ and $\Delta 133$ p53 $\gamma$, by RT-PCR. As shown in Fig. $3 \mathrm{E}$, the expression of p53 $\beta$ and $\Delta 133 \mathrm{p} 53 \gamma$ isoform was downregulated in matrine-treated cells compared with control. However, the expression of p53 $\beta$ and $\Delta 133 \mathrm{p} 53 \gamma$ isoform was upregulated in cells treated with matrine and 3-methyladenine (3-MA), a commonly used autophagy inhibitor. Conversely, the p53 $\gamma$ and $\Delta 133$ p53 mRNA variant was upregulated in matrine-treated cells and downregulated in cells treated with matrine and 3-MA. The expression of $\Delta 133 \mathrm{p} 53 \beta$ mRNA variant was attenuated in the cells exposed to matrine. However, no significant difference was observed in $\Delta 133 \mathrm{p} 53 \beta$ mRNA variant expression between cells treated with matrine and 3-MA and cells treated with matrine alone (Fig. 3F). These results imply that the autophagic process induced by matrine might contribute to the conversion of p53 splice variants, i.e., p53 $\beta$, p53 $\gamma, \Delta 133$ p53 and $\Delta 133$ p53 $\gamma$ expression.

AMPK inhibition switches matrine-induced autophagy to apoptosis. We assessed the role of AMPK in matrineinduced autophagy and apoptosis. Inactivation of AMPK by compound $c$, a specific inhibitor of AMPK, and RNA interference (RNAi) was conducted. The increase of LC3-II/ $\beta$-actin 
A
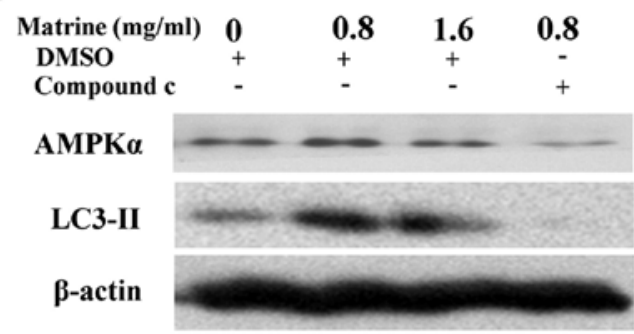

C
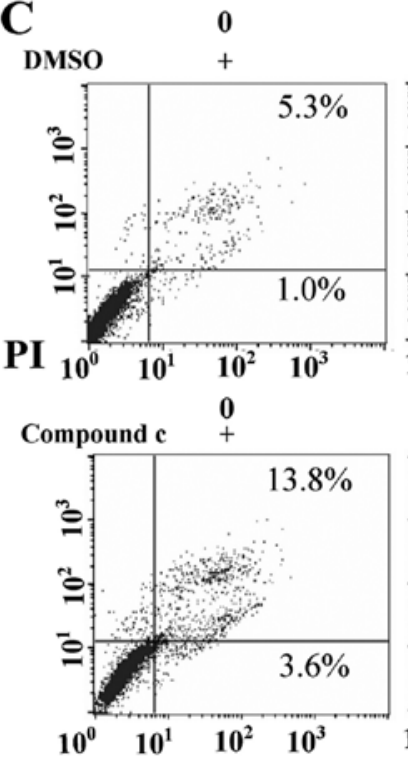

\section{8}

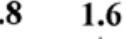

.6

0.8

$+$
B

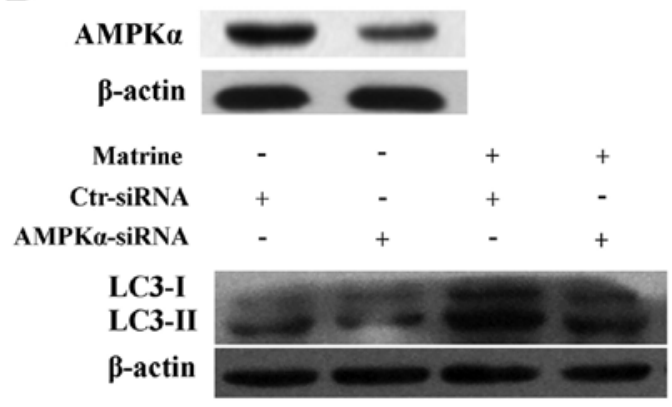

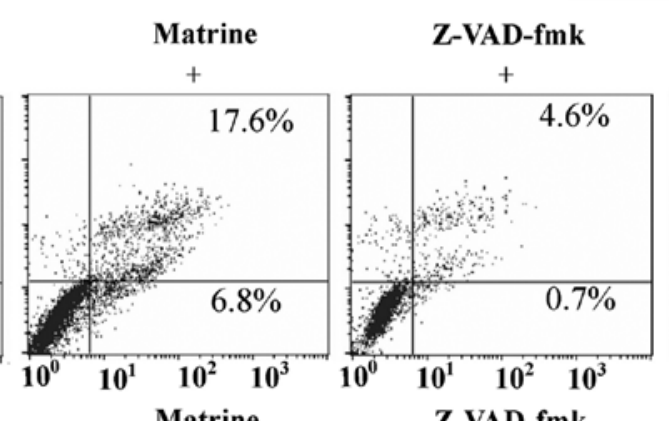
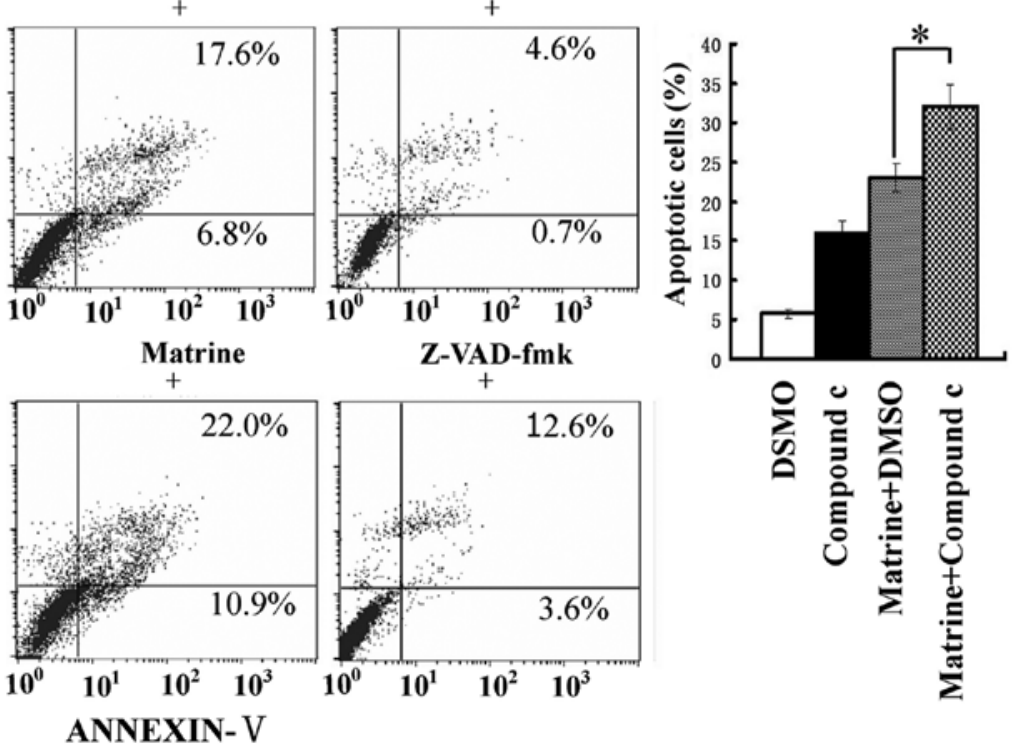

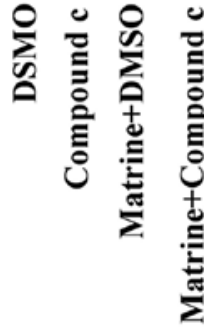

Figure 4. Inhibition of AMPK switches autophagy to apoptosis. Immunoblotting analysis confirmed AMPK $\alpha$ inhibition by compound c (A) and RNA interference (RNAi) (B) in HepG2 cells. After matrine treatment, AMPK inhibition by compound c (A) and RNAi (B) caused the reduction of LC3-II/actin ratio through western blotting. (C) Annexin V/PI analysis detected apoptosis of cells between matrine at $1.6 \mathrm{mg} / \mathrm{ml}$ alone and matrine cotreated with $10 \mu \mathrm{M}$ compound c or $20 \mu \mathrm{M}$ Z-VAD-fmk. Apoptotic cells are presented as the mean \pm SEM from three independent experiments $\left({ }^{*} \mathrm{p}<0.05\right)$.

ratio after matrine treatment was attenuated in cells treated with matrine and compound c, compared with cells treated with matrine alone. Similar results were obtained when blocking AMPK expression with AMPK- $\alpha$ siRNA (Fig. 4A and B), indicating that AMPK signaling was implicated in matrine-promoted autophagy in HepG2 cells. Moreover, there was an increase of apoptotic cells in matrine-treated cells in combination with compound $\mathrm{c}$ than matrine alone. In addition, this elevation in apoptosis level was downregulated by Z-VAD-fmk, a pan-caspase inhibitor (25) (Fig. 4C). Altogether, these results indicate AMPK inactivation triggers apoptosis through autophagy inhibition in HepG2 cells.

The IFN-signaling transduction is alleviated by autophagy inhibition and p53 activation, respectively. We further investigated the molecular mechanism of matrine-induced autophagy through cDNA array analysis. The expression of 280 genes were upregulated $\geq 2$-fold, and the expression of 58 genes were downregulated $\geq 2$-fold in matrine-treated cells at the dose of $0.8 \mathrm{mg} / \mathrm{ml}$. The 3 -fold downregulated or 4 -fold upregulated genes are shown in Table I. RT-PCR was used to examine expression of several representative genes, including interferon $\alpha$-inducible protein 27 (IFI27), interferon
Table I. Changes of gene expression induced by matrine at $0.8 \mathrm{mg} / \mathrm{ml}$ in HepG2 cells.

\begin{tabular}{lclc}
\hline Gene symbol & Fold change & Gene symbol & Fold change \\
\hline IFI27 & 24.23 & RARRES3 & 5.51 \\
HRASLS2 & 10.72 & CTSD & 5.39 \\
CFHR1 & 8.60 & DDX60L & 5.24 \\
TNFSF10 & 8.00 & SOD2 & 5.02 \\
ISG20 & 7.87 & STAT2 & 4.96 \\
TNFSF10 & 7.79 & CFB & 4.83 \\
IFITM1 & 7.38 & BDKRB2 & 4.79 \\
LAMP3 & 7.34 & HLA-E & 4.78 \\
ISG15 & 7.25 & C4BPA & 4.52 \\
C4A & 6.92 & ANG & 4.43 \\
CFH & 6.21 & PTGS1 & 4.34 \\
CCL5 & 6.14 & ARNT2 & 4.23 \\
SECTM1 & 5.97 & CARD16 & 4.19 \\
ATF3 & 5.96 & CASP1 & 4.06 \\
OAS3 & 5.90 & RBM3 & -3.11 \\
OAS1 & 5.81 & HEATR1 & -3.42 \\
SP110 & 5.54 & GKN2 & -3.73 \\
\hline
\end{tabular}


A

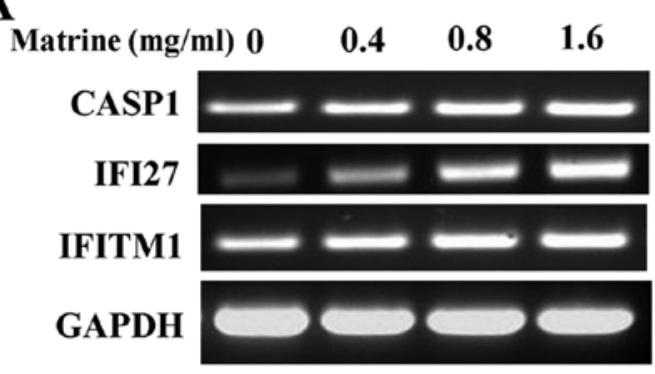

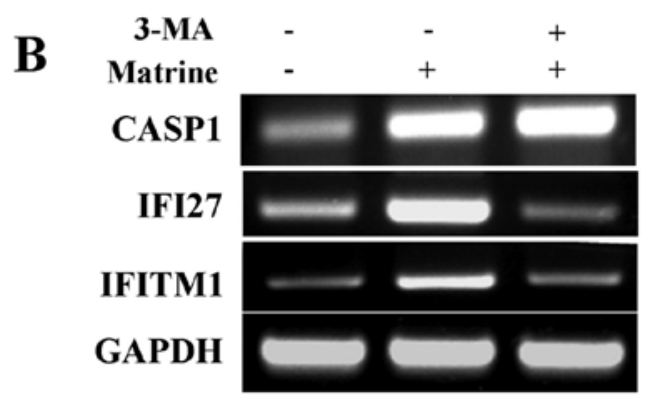

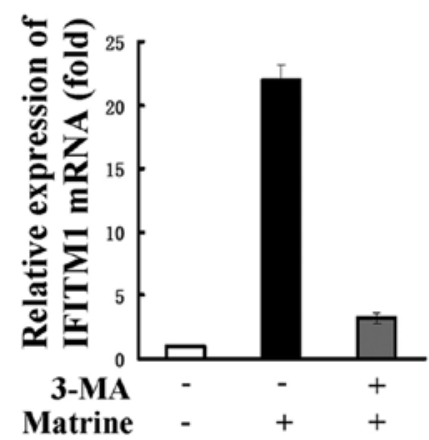

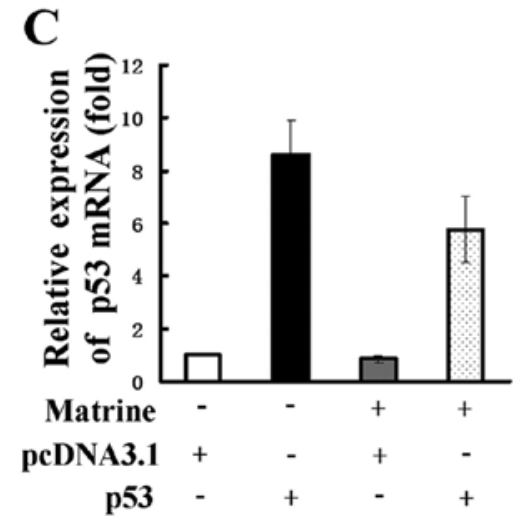
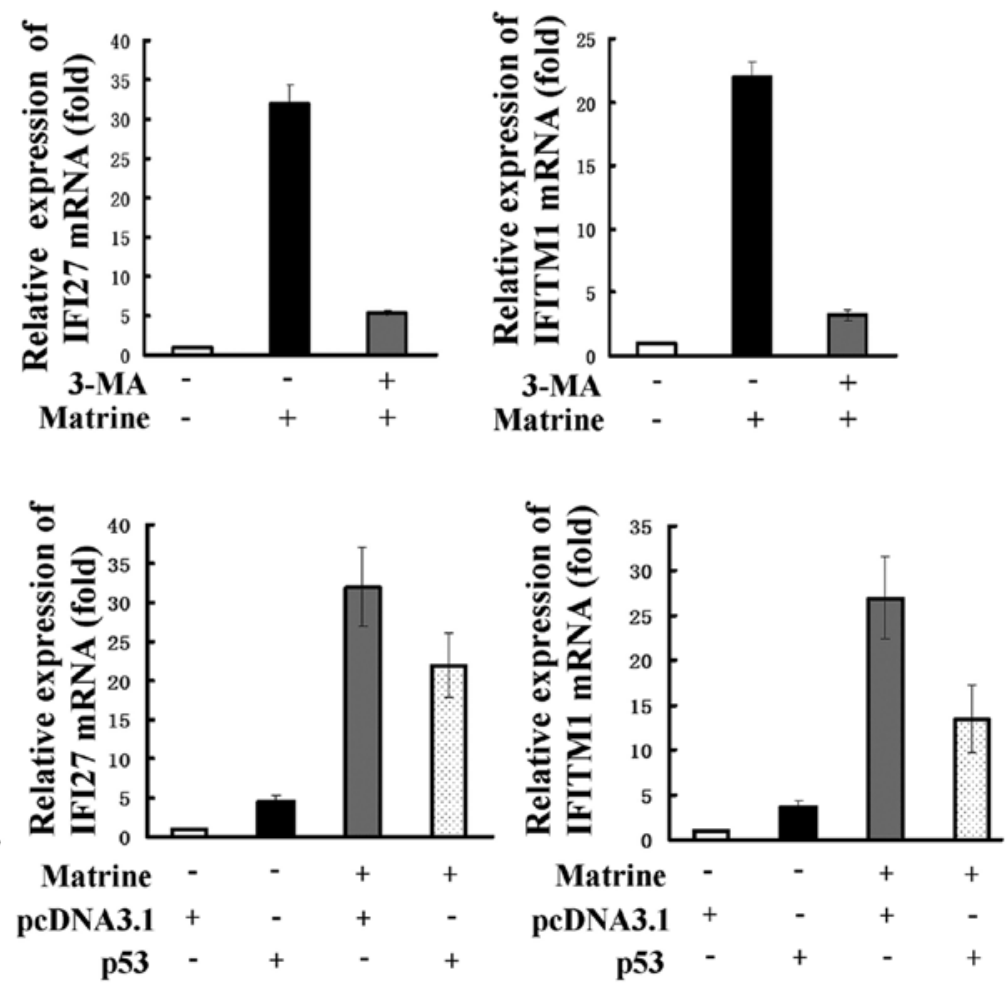

Figure 5. The IFN signaling transduction was alleviated by autophagy inhibition and p53 activation. (A) RT-PCR analysis of the expression of CASP1, IFI27 and IFITM1 in HepG2 cells after exposure to matrine in various concentrations, as compared with control. (B) Matrine at the dose of $0.8 \mathrm{mg} / \mathrm{ml}$ in combination with $5 \mathrm{mM}$ of 3-MA is presented. RT-PCR and real-time PCR analysis of CASP1, IFI27 and IFITM1 in the combination group, as contrast to matrine alone. (C) The cells initially were transiently transfected with p53 expression vector for $24 \mathrm{~h}$ followed by exposure to matrine at $0.8 \mathrm{mg} / \mathrm{ml}$ for $48 \mathrm{~h}$. Real-time PCR analysis of p53, IFI27 and IFITM1 in matrine-treated cells transfection with p53 overexpression vector as compared with control vector.

induced transmembrane protein 1 (IFITM1), and caspase 1 (CASP1). IFI27 and IFITM1 are two IFN-inducible genes and are reported to be related to autophagy (26). CASP1 is one of the apoptosis-related genes. The expression levels of IFI27, IFITM1 and CASP1 as revealed by RT-PCR analysis were consistent with those by cDNA array analysis (Fig. 5A). Next, 3-MA was used to detect whether the selected genes are related to matrine-induced autophagy. The increased expression of IFI27 and IFITM1 were significantly attenuated, but CASP1 expression were slightly strengthened after co-treatment with 3-MA, as shown by RT-PCR and real-time PCR (Fig. 5B). This suggests that the two IFN-inducible genes of IFI27 and IFITM1, but not CASP1, may be positively regulated by matrine-induced autophagy. We evaluated whether the role of IFN-mediated signaling transduction in hepatoma cells is modulated by p53. Real-time PCR showed that cells transfected with p53 overexpression plasmid had increased levels of IFI27 and IFITM1 expression in comparison with cells transfected with the control plasmid. After subjecting the cells transfected with the control plasmid to matrine, a more remarked increase of the two genes was observed and this increase was reversely inhibited by transfection with the $\mathrm{p} 53$ overexpressing plasmid (Fig. 5C).

Matrine-induced autophagy protects against death of HepG2 cells. It is unclear whether autophagy induction by matrine is protective or toxic. Initially, autophagy inhibition by 3-MA, a commonly used autophagy inhibitor, was confirmed by MDC staining in HepG2 cells (Fig. 6A). Subsequently, our study showed that 3-MA significantly enhanced matrine-induced apoptosis as showed by flow cytometry, which was alleviated by Z-VAD-fmk (Fig. 6B). Additionally, we explored whether blockage of autophagy by RNA interference (RNAi) enhanced matrine-induced cell death or not. After matrine treatment, beclin-1-siRNA transfectants had $24.2 \%$ increase of apoptotic cell death in comparison with control-siRNA transfectants $(12.9 \%)$ (Fig. 6C). These results indicated that matrine-induced autophagy has protective effects on hepatoma cells. 
A

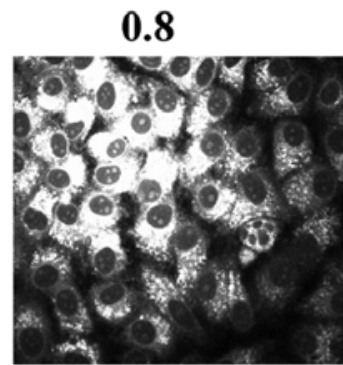

B
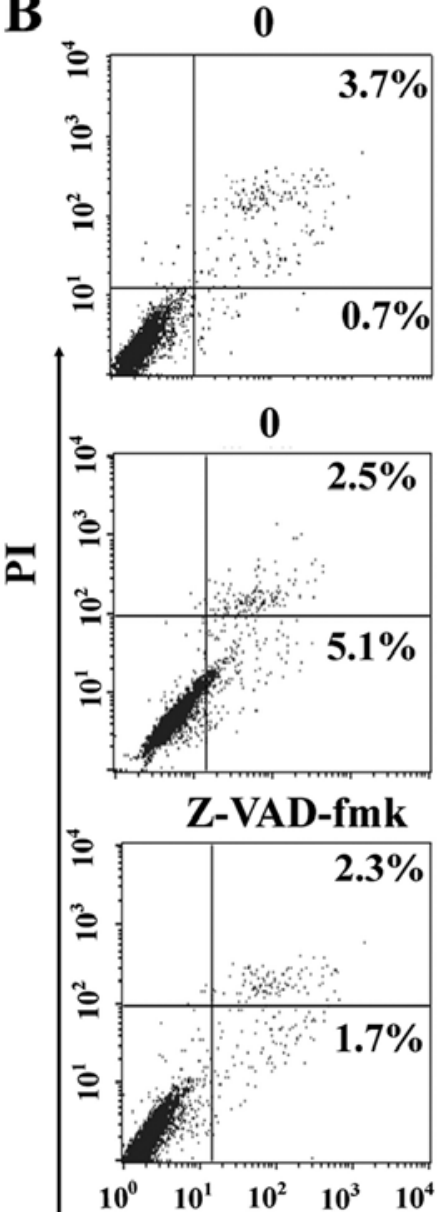

0.8+3-MA

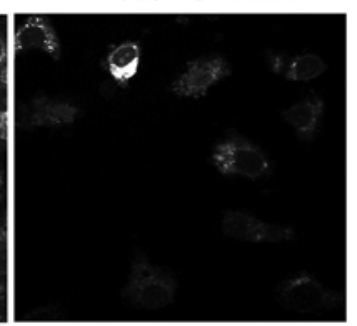

3-MA

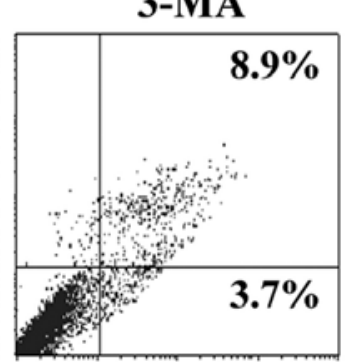

3-MA

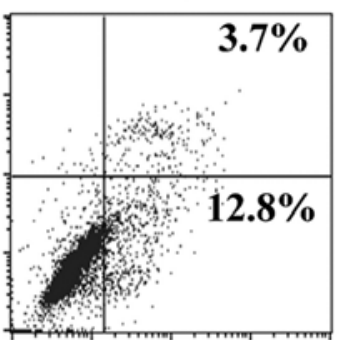

1.6+Z-VAD-fmk

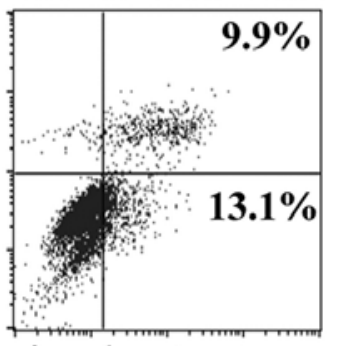

1.6

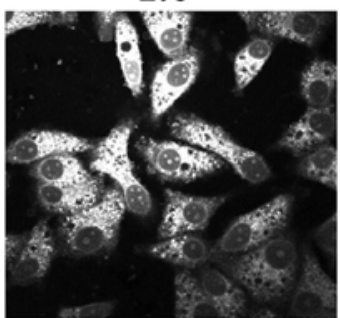

0.8

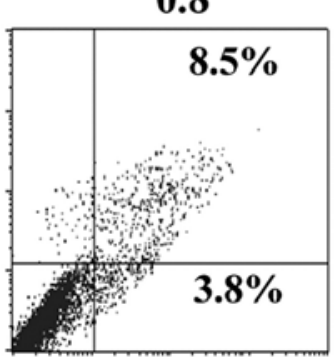

1.6

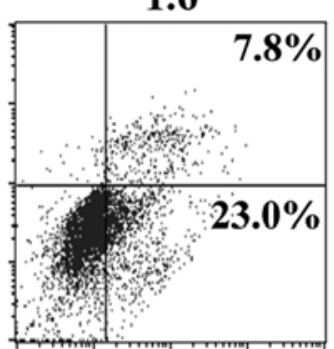

1.6+3-MA

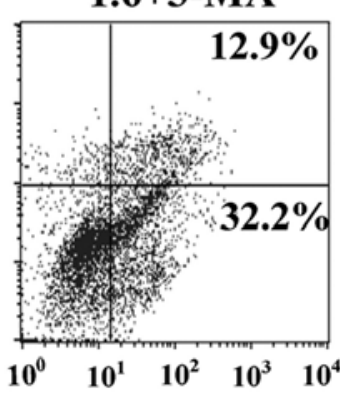

1.6+3-MA

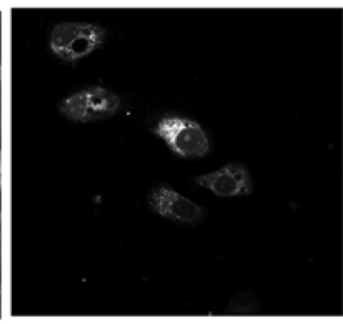

0.8+3-MA

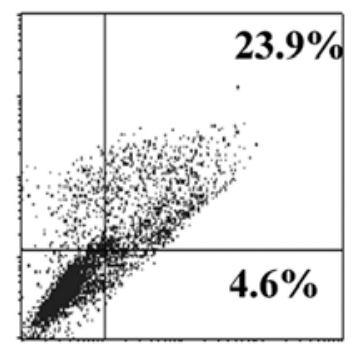

1.6

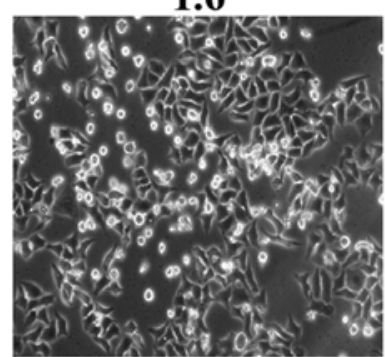

1.6+3-MA

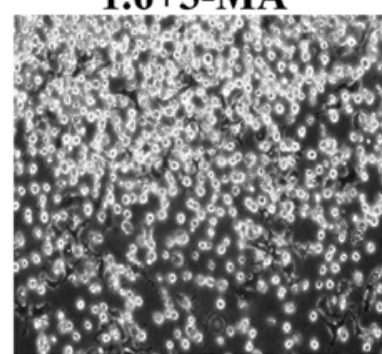

ANNEXIN-V

C

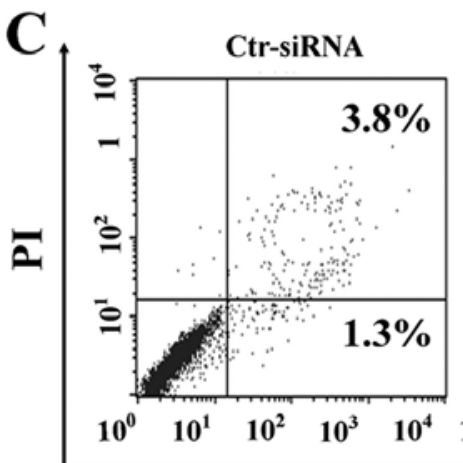

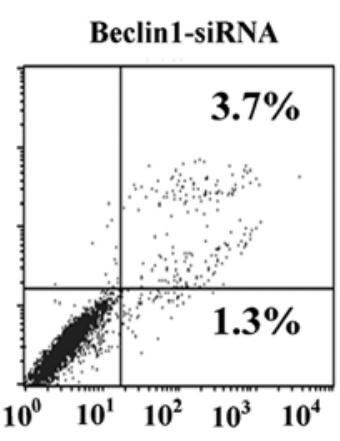

Matrine+Ctr-siRNA

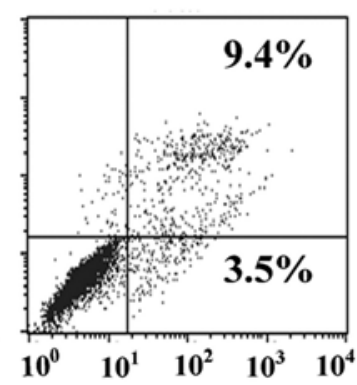

Matrine+Beclin1-siRNA

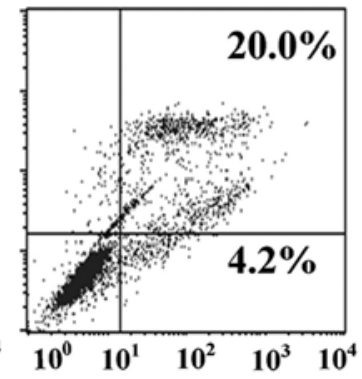

ANNEXIN-V

Figure 6. Matrine-induced autophagy promotes HepG2 cell survival and adaptation. (A) Matrine at the dose of $0.8 \mathrm{mg} / \mathrm{ml}(0.8) \mathrm{and} 1.6 \mathrm{mg} / \mathrm{ml}(1.6) \mathrm{in}$ combination with $5 \mathrm{mM}$ of $3-\mathrm{MA}$ is presented by $0.8+3 \mathrm{MA}$ or $1.6+3 \mathrm{MA}$. Representative images of MDC staining by confocal microscopy on cells of the combination groups $(0.8+3 \mathrm{MA}$ or $1.6+3 \mathrm{MA})$ compared to matrine treatment alone $(0.8$ or 1.6$)$ were obtained. (B) Annexin V/PI analysis detected apoptosis of cells between matrine alone ( 0.8 or 1.6) and matrine ( 0.8 or 1.6) cotreated with 3MA or Z-VAD-fmk. Representative light microscopic images were obtained from the combined group as compared with matrine alone. (C) After matrine treatment with $0.8 \mathrm{mg} / \mathrm{ml}$ concentration, apoptotic cell death was elevated in beclin1-siRNA-transfected cells (matrine+beclin1-siRNA) through Annexin V/PI analysis, as comparison with control-siRNA-transfected cells (matrine+control-siRNA). 


\section{Discussion}

Matrine has been reported to induce apoptosis and inhibit proliferation of cancer cells. However, the exact mechanism is still unknown. The present study demonstrates that matrine was able to affect both autophagy and apoptosis in human hepatoma cells. Our results were consistent with previous studies in C6 glioma cells and hepatoma cells $(5,6)$. However, our study showed that there was inverse correlation between apoptosis and autophagy in matrine-treated cells. Another finding of this study was that autophagy, but not apoptosis, predominated at low dose of matrine treatment. LC3 expression further confirmed this finding, suggesting that the initiation of apoptosis may be blocked by the autophagic system. Autophagy is usually activated by antineoplastic agents, yet it is not clear whether this is a futile effort for cellular preservation or a death mechanism. It has been reported that in matrine-treated C6 glioma cells, besides apoptosis, autophagy is another process of cell death whereas other studies demonstrate that autophagy inhibits apoptosis (11-14). What is the relationship between autophagy and apoptosis in matrine-treated hepatoma cells? To clarify this question, 3-MA and beclin-1 siRNA were administered to inhibit autophagy respectively, resulting in increment of apoptosis of HepG2 cells. We therefore conclude that matrineinduced autophagy may protect the cells against apoptosis.

The tumor suppressor p53 plays a dual role in autophagy, i.e., turning autophagy either on or off (15). It has been demonstrated that $\mathrm{p} 53$ inactivation by deletion, depletion or inhibition exerts its ability to stimulate autophagy (8). Consistent with these observations, our studies demonstrated that p53 inactivation was observed in HepG2 cells under matrine treatment, whereas p53 activation reversely suppressed the increased autophagic process induced by matrine. It is conceivable that p53 may negatively regulate matrine-induced autophagy in HCC cells. Inactivation of p53 has been recently shown to negatively regulate autophagy via AMPK signaling pathway, which is the same to autophagy induction by p53 activation (27). Similarly, we found that 553 overexpression lead to AMPK dephosphorylation and LC3-II conversion, suggesting that p53 negatively regulating autophagy may be via AMPK signaling pathway. Accumulating data have provided evidence that AMPK plays a key role in autophagy. Our earlier report showed that AMPK activation contributes to DNA damaged-induced autophagy in HepG2 cells (28). Consistently, in this study, we showed that AMPK was activated in matrine-treated HepG2 cells. Moreover, inactivation of AMPK by compoud c caused the conversion of LC3-II, implying that AMPK signaling may be involved in autophagy induction by matrine. These results suggest that AMPK activation is implicated in matrine-induced autophagy through p53 suppression. Then inhibition of AMPK by compound c clearly enhanced matrine-induced apoptosis in HepG2 cells. The disruption of AMPK may contribute to the switch from autophagy to apoptosis. Presumably, AMPK signaling transduction is a control switch from autophagy to apoptosis. Conceivably, increase of ATP levels in matrinetreated cells triggers AMPK loss and thereby switch autophagy which functions as maintaining cell survival to apoptotic cell death. AMPK initiates a series of downstream phosphorylation events and one major downstream event is to induce autophagy through inhibition of mTOR, a pivotal regulator for autophagy (29). Interestingly, we found that matrine induced autophagy may be independent of mTOR inhibition in HepG2 cells, but dependent of mTOR inhibition in SMMC-7721 cells. A similar result was observed where fangchinoline-induced autophagy is mediated by p53/AMPK signaling pathway in an mTOR-independent manner in both HepG2 and PLC/PRF/5 cells (30). Some small molecules, such as intracellular inositol or inositol 1,4,5-trisphosphate (IP3), have also been shown to activate mTOR-independent autophagy in vitro $(31,32)$. These results indicate that autophagy induction by matrine in HepG2 cells may not act through the mTOR signaling pathway, but rather through stimulating an unknown signaling pathway.

The p53 isoforms, including p53 $\beta, \mathrm{p} 53 \gamma, \Delta 133 \mathrm{p} 53$, $\Delta 133 p 53 \beta$ and $\Delta 133 p 53 \gamma$, are generated by alternative splicing of intron 9 and have been reported to be encoded in human p53 gene (20), and implicated in apoptosis (20). The $\Delta 133$ p53 and $\mathrm{p} 53 \beta$ splice variants have also been demonstrated to function as endogenous modulators of cellular senescence (33). However, it is unclear whether the p53 splice variants function in the increased autophagy in context-specific ways. In the present study, matrine treatment caused a decline of p53 $\beta$ and $\Delta 133 \mathrm{p} 53 \gamma$, but an elevation of $\mathrm{p} 53 \gamma$ and $\Delta 133 \mathrm{p} 53$. However, chemical inhibition of autophagy by 3-MA reversed the effects of these isoforms induced by matrine. This study, for the first time, suggests that autophagy induction by matrine may influence the splice variants. The p53 $\beta$ and $\Delta 133 \mathrm{p} 53 \gamma$ variants may be negatively controlled by autophagy, while the p53 $\gamma$ and $\Delta 133$ p53 isoforms may be positively controlled by autophagy. Nonetheless, chemical inhibition of autophagy had no effect on $\Delta 133 \mathrm{p} 53 \beta$ levels, implying that $\Delta 133 \mathrm{p} 53 \beta$ may not be regulated by matrine-induced autophagy. In this regard, p 53 variants perhaps was modulated by autophagy within a broader network. The interplay between autophagy and their role in p53 isoforms is still under investigation because our preliminary results are merely able to offer a clue at mRNA levels.

Autophagy has been implicated in the immune system. The induction of autophagy in immune cells serves as an innate immune response to defend against intruding pathogens $(34,35)$. In addition to regulation of the immune system, interferon (IFN)-inducible genes also play important roles in proliferation and tumorigenesis of tumor cells. IFITM1, a member of the interferon-induced transmembrane protein family, has been observed to induce tumor cell proliferation, and be upregulated in many kinds of tumors (36). IFI27, among the interferon $\alpha$-inducible proteins, is also a mitochondrial protein resistant to apoptosis. IFI27 may influence the innate immune responses of IFNs, and thus may be a novel marker of proliferation and cancer (37). Given that autophagy functions to promote cell survival and to resist apoptosis, what is the relationship between the IFN-inducible proteins and autophagy? Our results revealed a positive role for autophagy induction by matrine on the IFN-mediated signaling transduction. Conversely, a recent study indicates that HCV-induced autophagy inhibits the expression of IFN-stimulated genes, including IFI27, and that suppression of autophagy induces the IFN signaling pathway and apoptosis in HCV-infected hepatocytes (26). This study has demonstrated that autophagy can negate the IFN signaling pathway and serve as a defensive mechanism. This discrepancy may be partly explained by the distinct effect of IFN-stimulated genes on cell types. We further demonstrate that the IFN 
signaling transduction might be positively modulated by p53. Matrine treatment caused a significant elevation of the IFN-inducible genes, which were reversely downregulated by p53 activation. In addition to the central p53/AMPK pathway of autophagy induced by matrine, p53 mediated-autophagy is at least in part through the IFN-inducible genes in human hepatoma cells under matrine treatment.

In conclusion, matrine induces autophagy through p53/ AMPK signaling. In addition, matrine-induced autophagy might contribute to the regulation of the p53 splice variants and the IFN-inducible genes in human hepatoma cells. Pharmacological regulation of autophagy may improve the therapeutic effect of matrine against HCC and thereby improve survival of patients with malignancy.

\section{Acknowledgements}

This study was supported by National Natural Science Foundation of China (grant nos. 307728598 and 81273975). The authors thank Professor Hongchun Liu and Aiping Bai for professional support and help.

\section{References}

1. Luo C, Zhu Y, Jiang T, Lu X, Zhang W, Jing Q, Li J, Pang L, Chen K, Qiu F, et al: Matrine induced gastric cancer MKN45 cells apoptosis via increasing pro-apoptotic molecules of Bcl-2 family. Toxicology 229: 245-252, 2007.

2. Wan XY, Luo M, Li XD and He P: Hepatoprotective and antihepatocarcinogenic effects of glycyrrhizin and matrine. Chem Biol Interact 181: 15-19, 2009.

3. Guo D, Chen NN, Zhou P, Pan B and Hou LB: Suppressive effect of matrine on cell growth and decreases beta-catenin-dependent transcriptional activity in hepatoma cell line Hep3B. Zhong Yao Cai 33: 778-781, 2010 (In Chinese).

4. Zhang Y, Zhang H, Yu P, Liu Q, Liu K, Duan H, Luan G, Yagasaki $\mathrm{K}$ and Zhang G: Effects of matrine against the growth of human lung cancer and hepatoma cells as well as lung cancer cell migration. Cytotechnology 59: 191-200, 2009.

5. Zhang S, Qi J, Sun L, Cheng B, Pan S, Zhou M and Sun X: Matrine induces programmed cell death and regulates expression of relevant genes based on PCR array analysis in C6 glioma cells Mol Biol Rep 36: 791-799, 2009.

6. Zhang JQ, Li YM, Liu T, He WT, Chen YT, Chen XH, Li X, Zhou WC, Yi JF and Ren ZJ: Antitumor effect of matrine in human hepatoma $\mathrm{G} 2$ cells by inducing apoptosis and autophagy. World J Gastroenterol 16: 4281-4290, 2010.

7. Mizushima N: Autophagy: process and function. Genes Dev 21: 2861-2873, 2007.

8. Tasdemir E, Chiara Maiuri M, Morselli E, Criollo A, D'Amelio M, Djavaheri-Mergny M, Cecconi F, Tavernarakis N and Kroemer G: A dual role of p53 in the control of autophagy. Autophagy 4: 810-814, 2008

9. Kaushal GP, Kaushal V, Herzog C and Yang C: Autophagy delays apoptosis in renal tubular epithelial cells in cisplatin cytotoxicity. Autophagy 4: 710-712, 2008.

10. Huang S and Sinicrope FA: Celecoxib-induced apoptosis is enhanced by ABT-737 and by inhibition of autophagy in human colorectal cancer cells. Autophagy 6: 256-269, 2010.

11. Lee SB, Tong SY, Kim JJ, Um SJ and Park JS: Caspaseindependent autophagic cytotoxicity in etoposide-treated CaSki cervical carcinoma cells. DNA Cell Biol 26: 713-720, 2007.

12. Harhaji-Trajkovic L, Vilimanovich U, Kravic-Stevovic T, Bumbasirevic V and Trajkovic V: AMPK-mediated autophagy inhibits apoptosis in cisplatin-treated tumor cells. J Cell Mol Med 13: 3644-3654, 2009.

13. Nishikawa T, Tsuno NH, Okaji Y, Shuno Y, Sasaki K, Hongo K, Sunami E, Kitayama J, Takahashi K and Nagawa H: Inhibition of autophagy potentiates sulforaphane-induced apoptosis in human colon cancer cells. Ann Surg Oncol 17: 592-602, 2010.

14. Abedin MJ, Wang D, McDonnell MA, Lehmann U and Kelekar A: Autophagy delays apoptotic death in breast cancer cells following DNA damage. Cell Death Differ 14: 500-510, 2007.
15. Levine B and Abrams J: p53: the Janus of autophagy? Nat Cell Biol 10: 637-639, 2008.

16. Meijer AJ and Codogno P: Signalling and autophagy regulation in health, aging and disease. Mol Aspects Med 27: 411-425, 2006.

17. Feng Z, Zhang H, Levine AJ and Jin S: The coordinate regulation of the p53 and mTOR pathways in cells. Proc Natl Acad Sci USA 102: 8204-8209, 2005.

18. Zhang Q, Zhao XH and Wang ZJ: Cytotoxicity of flavones and flavonols to a human esophageal squamous cell carcinoma cell line (KYSE-510) by induction of $\mathrm{G} 2 / \mathrm{M}$ arrest and apoptosis. Toxicol In Vitro 23: 797-807, 2009.

19. Yang YH, Dudoit S, Luu P, Lin DM, Peng V, Ngai J and Speed TP: Normalization for cDNA microarray data: a robust composite method addressing single and multiple slide systematic variation. Nucleic Acids Res 30: e15, 2002.

20. Bourdon JC, Fernandes K, Murray-Zmijewski F, Liu G, Diot A, Xirodimas DP, Saville MK and Lane DP: p53 isoforms can regulate p53 transcriptional activity. Genes Dev 19: 2122-2137, 2005.

21. Liu T, Song Y, Chen H, Pan S and Sun X: Matrine inhibits proliferation and induces apoptosis of pancreatic cancer cells in vitro and in vivo. Biol Pharm Bull 33: 1740-1745, 2010.

22. Han Y, Zhang S, Wu J, Yu K, Zhang Y, Yin L and Bi L: Matrine induces apoptosis of human multiple myeloma cells via activation of the mitochondrial pathway. Leuk Lymphoma 51: 1337-1346, 2010.

23. Kabeya Y, Mizushima N, Ueno T, Yamamoto A, Kirisako T, Noda T, Kominami E, Ohsumi Y and Yoshimori T: LC3, a mammalian homologue of yeast Apg8p, is localized in autophagosome membranes after processing. EMBO J 19: 5720-5728, 2000.

24. Mizushima N: Methods for monitoring autophagy. Int J Biochem Cell Biol 36: 2491-2502, 2004.

25. Slee EA, Zhu H, Chow SC, MacFarlane M, Nicholson DW and Cohen GM: Benzyloxycarbonyl-Val-Ala-Asp (OMe) fluoromethylketone (Z-VAD.FMK) inhibits apoptosis by blocking the processing of CPP32. Biochem J 315: 21-24, 1996.

26. Shrivastava S, Raychoudhuri A, Steele R, Ray R and Ray RB: Knockdown of autophagy enhances the innate immune response in hepatitis $C$ virus-infected hepatocytes. Hepatology 53: 406-414, 2011.

27. Tasdemir E, Maiuri MC, Galluzzi L, Vitale I, DjavaheriMergny M, D'Amelio M, Criollo A, Morselli E, Zhu C, Harper F, et al: Regulation of autophagy by cytoplasmic p53. Nat Cell Biol 10: 676-687, 2008.

28. Xie BS, Zhao HC, Yao SK, Zhuo DX, Jin B, Lv DC, Wu CL, Ma DL, Gao C, Shu XM, et al: Autophagy inhibition enhances etoposide-induced cell death in human hepatoma G2 cells. Int J Mol Med 27: 599-606, 2011.

29. Meley D, Bauvy C, Houben-Weerts JH, Dubbelhuis PF, Helmond MT, Codogno P and Meijer AJ: AMP-activated protein kinase and the regulation of autophagic proteolysis. J Biol Chem 281: 34870-34879, 2006.

30. Wang N, Pan W, Zhu M, Zhang M, Hao X, Liang G and Feng Y: Fangchinoline induces autophagic cell death via p53/sestrin2/ AMPK signaling in human hepatocellular carcinoma cells. Br J Pharmacol 164: 731-742, 2011.

31. Rubinsztein DC, Gestwicki JE, Murphy LO and Klionsky DJ: Potential therapeutic applications of autophagy. Nat Rev Drug Discov 6: 304-312, 2007.

32. Botti J, Djavaheri-Mergny M, Pilatte $\mathrm{Y}$ and Codogno P: Autophagy signaling and the cogwheels of cancer. Autophagy 2: 67-73, 2006.

33. Fujita K, Mondal AM, Horikawa I, Nguyen GH, Kumamoto K, Sohn JJ, Bowman ED, Mathe EA, Schetter AJ, Pine SR, et al: p53 isoforms Delta133p53 and p53beta are endogenous regulators of replicative cellular senescence. Nat Cell Biol 11: 1135-1142, 2009.

34. Weidberg $\mathrm{H}$ and Elazar Z: TBK1 mediates crosstalk between the innate immune response and autophagy. Sci Signal 4: pe39, 2011.

35. Deretic V: Autophagy in innate and adaptive immunity. Trends Immunol 26: 523-528, 2005.

36. Yu F, Ng SS, Chow BK, Sze J, Lu G, Poon WS, Kung HF and Lin MC: Knockdown of interferon-induced transmembrane protein 1 (IFITM1) inhibits proliferation, migration, and invasion of glioma cells. J Neurooncol 103: 187-195, 2011.

37. Suomela S, Cao L, Bowcock A and Saarialho-Kere U: Interferon alpha-inducible protein 27 (IFI27) is upregulated in psoriatic skin and certain epithelial cancers. J Invest Dermatol 122: 717-721, 2004. 